Pesq. Vet. Bras. 30(1):67-72, janeiro 2010

\title{
Paratuberculose em caprinos e ovinos no Brasil ${ }^{1}$
}

\author{
Diego M. Oliveira², Franklin Riet-Correa ${ }^{2}$, Glauco J.N. Galiza², Adriana C.O. \\ Assis $^{2}$, Antônio F.M. Dantas ${ }^{2}$, Paulo M. Bandarra ${ }^{3}$ e Felicio Garino Jr²
}

\begin{abstract}
Oliveira D.M., Riet-Correa F., Galiza G.J.N., Assis A.C.O., Dantas A.F.M., Bandarra P.M. \& Garino Jr F. 2010. [Paratuberculosis in goats and sheep in Brazil.] Paratuberculose em caprinos e ovinos no Brasil. Pesquisa Veterinária Brasileira 30(1):6772. Hospital Veterinário, Centro de Saúde e Tecnologia Rural, Campus de Patos, Universidade Federal de Campina Grande, Patos, PB 58700-000, Brazil. E-mail: franklin.riet@pq.cnpq.br

This paper reports paratuberculosis in sheep and goats for the first time in Brazil. On Farm 1 in a flock of 33 goats and 13 sheep, one adult female goat presented progressive weight loss during about one year, and soft feces during one month before death. All the animals from the flock were submitted to the comparative tuberculin test. One sheep was positive to the avian tuberculin $(2.2 \%)$ and in two the results were inconclusive. On Farm 2 , in a flock of 200 sheep and 80 goats, one adult ewe presented progressive weight loss during about one year, and soft feces during 20 days before death. All sheep older than four months of age and 23 goats were submitted to tuberculin test with avian tuberculin; $47(25.4 \%)$ sheep were positive, $115(61.5 \%)$ had inconclusive results, and $25(13.4 \%)$ were negative. No positive tuberculin test were observed in the goats, but in $11(47.8 \%)$ the test was inconclusive and in $12(52.2 \%)$ was negative. At necropsy both affected animals had enlarged mesenteric lymph nodes. In the affected sheep, the gut wall was thickened and corrugated, mainly in the ileum and ileocecal valve. Histologically, granulomas with mainly foamy macrophages were observed in the lamina propria and submucosa of the gut, in mesenteric lymph nodes, and in the goat also in the liver. One tuberculin positive sheep and one tuberculin negative goat from Farm 1 were euthanized and necropsied. A mild thickened of the intestinal wall was observed grossly in both animals. Inflammatory infiltrate with mainly lymphocytes was observed on the submucosa and lamina propria of the gut. In the four cases acid-alcohol positive rods, positive for Mycobacterium spp. on immunohistochemical examination were observed in macrophages and lymphocytes. New studies are necessary to know the prevalence and economical impact of paratuberculosis in goats and sheep in Brazil, to determine control measures, and to evaluate the risk of human transmission.
\end{abstract}

INDEX TERMS: Johne's disease, Mycobacterium avium subsp. paratuberculosis, paratuberculosis, sheep, goats.

RESUMO.- Este trabalho relata, pela primeira vez no Brasil, no Estado da Paraíba, paratuberculose em dois rebanhos com criação conjunta de caprinos e ovinos. Na Fa-

\footnotetext{
${ }^{1}$ Recebido em 25 de julho de 2009.

Aceito para publicação em 4 de setembro de 2009.

${ }^{2}$ Hospital Veterinário, CSTR, Universidade Federal de Campina Grande (UFCG), Campus de Patos, 58700-000 Patos, PB, Brasil. *Autor para correspondência: franklin.riet@pq.cnpq.br

${ }^{3}$ Setor de Patologia Veterinária, Universidade Federal do Rio Grande do Sul (UFRGS), Av. Bento Gonçalves 9090, Bairro Agronomia, Porto Alegre, RS 91540-000, Brasil.
}

zenda 1 , de um rebanho de 33 caprinos e 13 ovinos, uma cabra adulta apresentou emagrecimento progressivo por aproximadamente um ano e fezes pastosas um mês antes da morte. Todos os animais do rebanho foram tuberculinizados com a prova comparativa. Um ovino $(2,2 \%)$ teve resultado positivo à tuberculina aviar e em dois o teste foi inconclusivo. Na Fazenda 2, com 200 ovinos e 80 caprinos, foi afetada uma ovelha adulta que apresentou emagrecimento progressivo por aproximadamente um ano e fezes pastosas por aproximadamente 20 dias. Todos os ovinos com mais de 4 meses de idade e 23 
caprinos foram tuberculinizados com tuberculina aviar; em $47(25,4 \%)$ o resultado foi positivo, em $115(61,5 \%)$ inconclusivo e em 25 (13,4\%) negativo. Entre as cabras não houve nenhuma positiva à tuberculina aviar, mas em $11(47,8 \%)$ o teste foi inconclusivo e em $12(52,2 \%)$ foi negativo. Na necropsia dos dois animais com sinais clínicos os linfonodos mesentéricos estavam aumentados de tamanho e edemaciados. O ovino afetado da Fazenda 2, apresentou espessamento e enrugamento da mucosa do intestino, principalmente no íleo e válvula íleo-cecal. Microscopicamente o caprino e o ovino com sinais clínicos apresentaram lesões semelhantes, caracterizadas por granulomas com predominância de macrófagos espumosos, na lâmina própria e submucosa do intestino e linfonodos mesentéricos. O ovino positivo à tuberculina e um caprino negativo na Fazenda 1 foram eutanasiados e apresentaram discreto espessamento da mucosa do íleo. $\mathrm{Na}$ histologia foi observado infiltrado preferentemente linfocítico. Em todos os casos dentro de macrófagos e linfócitos havia bacilos ácool-ácidos resistentes, positivos na imunohistoquímica para Mycobacterium spp. Sugere-se a necessidade de estudar a prevalência de paratuberculose em rebanhos de caprinos e ovinos no Brasil, determinar medidas de controle e avaliar a possibilidade de transmissão para humanos.

TERMOS DE INDEXAÇÃO: Doença de Johne, paratuberculose, caprinos, ovinos, Mycobacterium avium subsp paratuberculosis.

\section{INTRODUÇÃO}

A paratuberculose (doença de Johne) é uma enfermidade infecciosa crônica, incurável, que ocorre em todos os continentes, afetando principalmente ruminantes domésticos e, com menor freqüência, ruminantes selvagens, eqüinos, suínos, lebres, raposas e roedores. O agente etiológico é Mycobacterium avium subsp. paratuberculosis (MAP) que causa enterite e linfadenite granulomatosas (Clarke 1997, Harris \& Barletta 2001, Barker 2007, RietCorrea \& Driemeier 2007, Moravkova et al. 2008).

A doença é responsável por grandes perdas econômicas. Nos EUA o prejuízo anual com esta enfermidade é estimado em US\$200-250 milhões (Ott et al. 1999). Há fortes indícios de que MAP seja o agente causal da ileocolite granulomatosa de humanos conhecida como doença de Crohn (Chiodini \& Rossiter 1996, Chamberlin et al. 2001).

Em ruminantes, a infecção geralmente ocorre logo após o nascimento (Clarke \& Little 1996), principalmente pela ingestão de alimentos e água contaminados e leite e colostro de animais infectados. Há também transmissão pela via intra-uterina (Silva 1968, Radostits et al. 2007). Os sinais clínicos ocorrem, muitas vezes, logo após estresse relacionado ao transporte, parto e aleitamento, diminuição na ingestão alimentar, imunossupressão e doenças intercorrentes. Os animais criados em sistema intensivo e aqueles que estão em solos ácidos são mais suscetíveis (Taylor et al. 1981, Radostits et al. 2007).
Em ovinos e caprinos a doença clínica geralmente se manifesta em animais acima de um ano de idade (Clarke 1997). Apenas ocasionalmente animais mais jovens são afetados (Kumar et al. 2007, Singh et al. 2007). A doença manifesta-se principalmente por emaciação progressiva. Em ambas as espécies, a diarréia não é grave ou está ausente, um aspecto diferente dos bovinos nos quais a diarréia é um sinal clínico característico (Radostits et al. 2007).

Em ovinos que apresentam sinais clínicos, as lesões histológicas variam, ocorrendo duas formas da doença: (1) a tuberculóide (lesão paucibacilar) com uma forte resposta imunológica celular, e com poucas micobactérias ou mesmo ausência delas nas lesões; (2) a lepromatosa (lesão multibacilar) com forte resposta imunológica humoral, contendo numerosas micobactérias intracelulares. As duas formas associadas, chamadas de formas limítrofes (borderline forms), tendem a apresentar os sinais clínicos mais graves (Clarke \& Little 1996, Pérez et al. 1996). Em caprinos as lesões podem ser classificadas como focais ou difusas do tipo multibacilar, linfocítica ou mista (Corpa et al. 2000).

No Brasil, têm sido diagnosticados casos de paratuberculose, em bovinos importados e naqueles nascidos no país, filhos de pais importados, nas regiões sul e sudeste (Ilha et al. 1998, Riet-Correa \& Driemeier 2007), mas não há dados sobre a prevalência da enfermidade. No nordeste, em Pernambuco e Paraíba, também ocorre a paratuberculose em bovinos, sem histórico de importação (Mota et al. 2007, Oliveira et al. 2008). No Brasil, não há relatos de casos espontâneos em caprinos e ovinos, mas a paratuberculose foi reproduzida experimentalmente em ovinos (Silva 1968) e caprinos (Poester \& Ramos 1994) com isolamentos de micobactérias de origem bovina.

O objetivo deste trabalho é relatar a ocorrência de paratuberculose em caprinos e ovinos no nordeste do Brasil e descrever o quadro clínico-patológico da enfermidade.

\section{MATERIAL E MÉTODOS}

Os dados epidemiológicos foram coletados junto aos produtores, em duas fazendas (1 e 2), no semiárido da Paraíba, onde foi diagnosticada a doença. Na Fazenda 1 havia um rebanho de 33 caprinos da raça Moxotó e cruzas, e 13 ovinos da raça Santa Inês, com idade entre quatro meses a oito anos. Os animais eram mantidos em confinamento e alimentados com concentrados (farelos de trigo e de milho e ração comercial) e feno de capim Tifton (Cynodon dactylon). Na Fazenda 2 havia 80 caprinos cruzas e 200 ovinos, da raça Santa Inês, de um mês à seis anos de idade. Os animais eram confinados e suplementados com concentrado à noite e durante o dia permaneciam a campo.

De um caprino e um ovino com sinais clínicos, foram coletadas fezes da ampola retal para a contagem dos ovos por grama (OPG) de fezes de parasitas gastrintestinais. Foram também realizados nesses animais, raspados de pele em áreas de alopecia, para o diagnóstico de dermatomicose, por exame direto do pêlo, e de dermatofilose pela coloração de azul de metileno.

Foi realizado teste de tuberculina nos ovinos e caprinos acima de quatro meses de idade. Na Fazenda 1 todos os animais dessa faixa etária foram submetidos ao teste, sendo 13 
ovinos e 33 caprinos. Na fazenda 2 foram tuberculinizados 187 ovinos e 23 caprinos. O teste da tuberculinização foi feito após tricotomia; em seguida era mensurada a espessura da dobra da pele com o cutímetro. Após 72 horas foi feita outra medida da espessura da dobra da pele. Na Fazenda 1 foi utilizado o teste cutâneo comparativo, na região da escapula média, com inoculação dos derivados protéico aviário $(0,1 \mathrm{ml}$, com 2.500UI) e bovino (0,1 ml, com 5.000Ul). Foram considerados positivos animais com reação à tuberculina aviar de mais de $4 \mathrm{~mm}$ do que a reação da tuberculina bovina. Reações com diferença entre a bovina e a aviária menores que $2 \mathrm{~mm}$ foram consideradas negativas e entre 2 e 3,9 $\mathrm{mm}$ inconclusivas. Na Fazenda 2 apenas a tuberculina aviária (PPD-aviário) foi utilizada. Animais com aumento da espessura da pele de menos de $2 \mathrm{~mm}$ foram considerados negativos e com mais de $4 \mathrm{~mm}$, positivos. Leituras intermediárias foram consideradas inconclusivas.

O Ovino 2.1, da Fazenda 2, que apresentava sinais clínicos, o Ovino 1.1 e o Caprino 1.2, da Fazenda 1, que não apresentavam sinais, foram eutanasiados e necropsiados. Também foi necropsiado o Caprino 1.1, da Fazenda 1 que morreu espontaneamente. Do Caprino 1.1 foram coletadas amostras de íleo, jejuno, linfonodos mesentéricos, fígado, abomaso, pulmão, rins, baço, coração e pele. Dos demais animais (Caprino $1.2 \mathrm{e}$ Ovinos 1.1 e 2.1) foram coletados fragmentos do duodeno (5 $\mathrm{cm}$ de distância do piloro), jejuno (amostras, da porção inicial, média e final), íleo (amostras, com 5 e $10 \mathrm{~cm}$ de distância da válvula ileocecal, válvula ileocecal, ceco, cólon, reto $(a 10 \mathrm{~cm}$ do ânus), linfonodos mesentéricos, pré-escapular, retrofaríngeos, mediastínicos, hepático, supra-mamário e ilíaco medial, fígado, vesícula biliar, baço, pâncreas, estômago e pré-estômagos, adrenal, rins, pulmão, coração, aorta, tireóide, útero, glândula mamária e sistema nervoso central. Todos os órgãos coletados foram fixados em formol tamponado a 10\%. Após a fixação as amostras foram incluídas em parafina, cortadas a $5 \mu \mathrm{m}$ e coradas com Hematoxilina e Eosina. Os fragmentos de íleo, válvula ileocecal e linfonodo mesentérico foram coradas pela técnica de Ziehl-Neelsen, como também o fígado do Caprino 1.1.

Cortes histológicos de íleo, válvula ileocecal e linfonodos mesentéricos foram submetidas à imuno-histoquímica. $\mathrm{O}$ bloqueio da peroxidase endógena foi feito pela incubação das lâminas em solução de peróxido de hidrogênio a 3\% em água destilada por 15 minutos em temperatura ambiente. A recuperação antigênica foi realizada com protease $\mathrm{XIV}^{4}$ durante 15 minutos. Para a diminuição das ligações inespecíficas ("background"), as lâminas foram tratadas com leite desnatado $5 \%$ em água destilada durante 15 minutos. Os cortes foram incubados com o anticorpo primário policlonal anti-mycobacterium tuberculosis (Genetex, GTX20905) na diluição de 1:200 em PBS durante uma hora à $37^{\circ} \mathrm{C}$. Em seguida, foi utilizado anticorpo secundário biotinalado por 20 minutos e depois tratados com o conjugado estreptavidinaperoxidase $^{6}$ por mais 20 minutos. Como cromógeno foi utilizado o 3,3 - diaminobenzidina ${ }^{7}$ (DAB). Controles positivos foram utilizados simultaneamente no procedimento.

\footnotetext{
${ }^{4}$ Sigma Chemical Company, Poole, United Kingdom (UK).

${ }^{5}$ Molico, Araçatuba, São Paulo, Brasil.

${ }^{6}$ Estreptavidina-peroxidase LSAB, Dako, Carpinteria, California, United States of America (USA).

7 3,3 - diaminobenzidina, Dako, Carpinteria, California, USA.
}

\section{RESULTADOS}

\section{Epidemiologia e sinais clínicos}

$\mathrm{Na}$ Fazenda 1, a doença foi diagnosticada em uma cabra (Caprino 1.1), de três anos de idade, que apresentava emagrecimento há aproximadamente um ano. No momento do exame estava caquética (Fig.1), com desi-

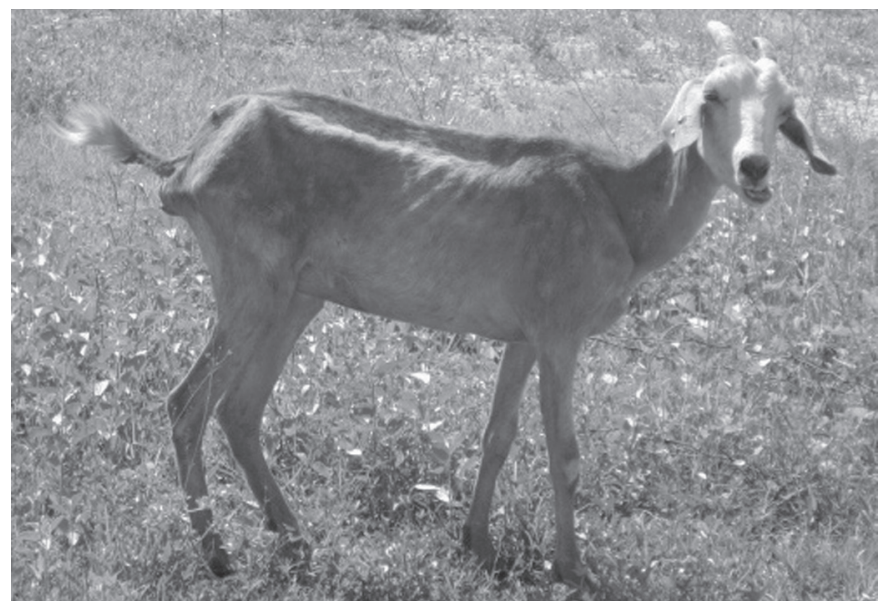

Fig.1. Cabra com caquexia devido à paratuberculose (Caprino 1.1).

dratação de aproximadamente 5\%, mucosas oculares pálidas, dispnéia mista, tosse seca, arritmia cardíaca, edema submandibular e apetite caprichoso. O pêlo estava sem brilho, áspero e quebradiço e apresentava áreas de alopecia bilateral, com formação de crostas na região toracolombar. Foi realizada tuberculinização com PPD bovino, com resultado negativo. A cabra morreu após um mês, durante o qual apresentou fezes pastosas.

O Ovino 2.1, proveniente da Fazenda 2, foi encaminhado ao Hospital Veterinário da UFCG em Patos, por apresentar emagrecimento. Tinha três anos de idade e os sinais tinham se agravado 20 dias após o parto. Ao exame clínico observou-se caquexia (Fig.2), fezes pastosas e áreas bilaterais de alopecia na região dorsal. No

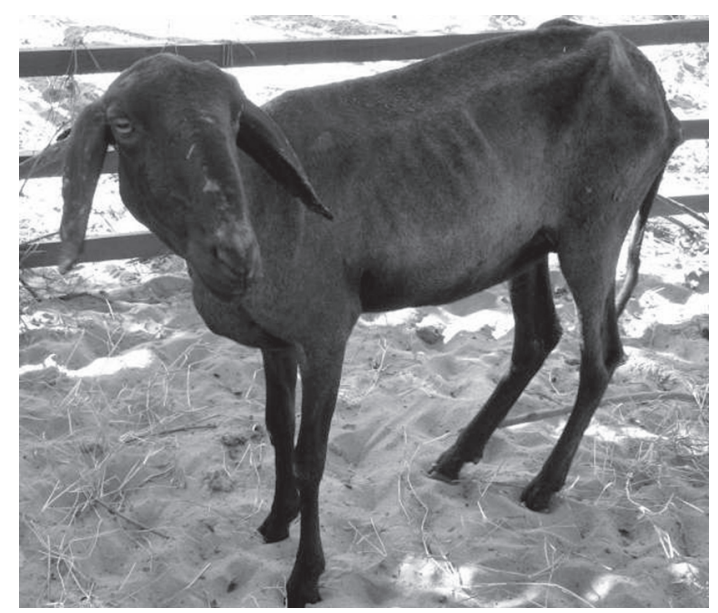

Fig.2. Ovelha com caquexia devido à paratuberculose (Ovino 2.1). 
teste de tuberculina com PPD aviaria, o resultado foi positivo.

Os esfregaços da pele do Caprino 1.2 e do Ovino 2.1 foram negativos para fungos e Dermatophilus spp. O Caprino 1.1 apresentava infestação moderada de Eimeria spp. e as fezes dos dois animais foram negativas para parasitas gastrintestinais.

\section{Tuberculinização}

Na Fazenda 1, um ovino (Ovino 1.1), com idade de quatro anos e estado corporal bom, foi positivo a PPD aviária (1/46; $2,2 \%)$, na prova comparativa. Em um caprino e um ovino o resultado foi inconclusivo. Na Fazenda 2, 47 (25,1\%) ovinos com idade entre cinco meses a cinco anos e estado corporal regular a bom foram positivos a PPD aviária; em $115(61,5 \%)$ o resultado foi inconclusivo e em 25 (13,4\%) foi negativo. Nos caprinos foi obtido resultado inconclusivo em $11(47,8 \%)$ e resultado negativo em 12 (52,2\%).

\section{Alterações macroscópicas}

Todos os animais apresentavam os linfonodos mesentéricos, aumentados de volume, edemaciados e ao corte, nódulos esbranquiçados salientes no córtex, de intensidade leve a acentuada. No Caprino 1.1 e Ovino 2.1 foi observada atrofia da serosa da gordura pericárdica. O Caprino 1.1 apresentava edema do mesentério e o Ovino 2.1, além desta

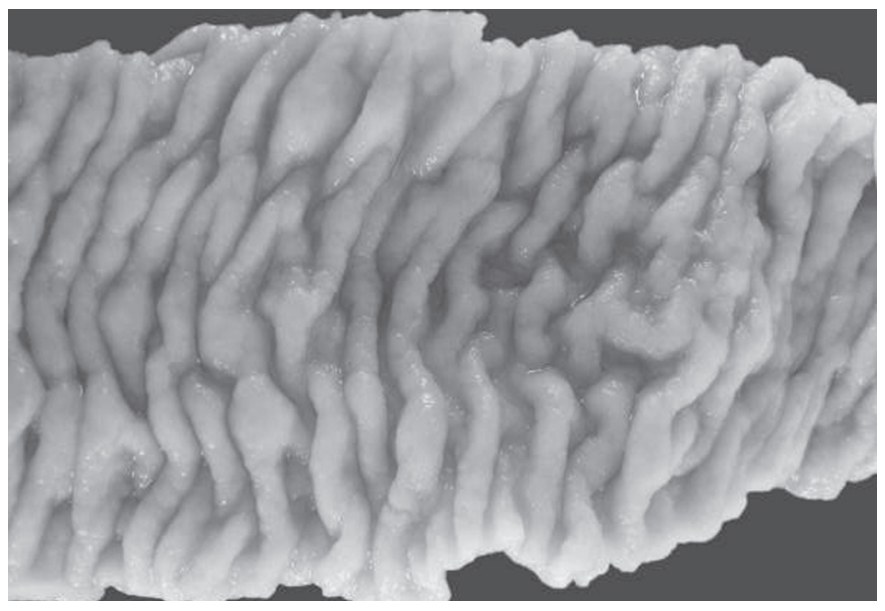

Fig.3. A mucosa do íleo está espessada, irregular e enrugada formando pregas transversais, semelhante às circunvoluções cerebrais (Ovino 2.1).

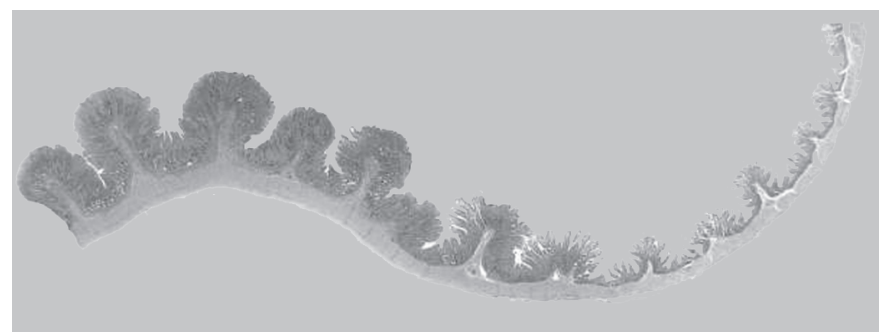

Fig.4. Na metade esquerda da figura, a mucosa, submucosa e lâmina própria, do jejuno do Ovino 2.1, apresentam espessamento segmentar. HE, visão submacroscópica. alteração, também apresentava $700 \mathrm{ml}$ de líquido na cavidade abdominal, de coloração citrina e consistência gelatinosa. O Ovino 2.1 apresentava segmentos de $2-22 \mathrm{~cm}$ de comprimento, do jejuno e íleo com a mucosa espessada (com até $0,5 \mathrm{~cm}$ de espessura), irregular e enrugada (Fig.34), formando pregas transversais que não desapareciam ao se tracionar o intestino, semelhante às circunvoluções cerebrais. Nessas áreas, ao corte do intestino, observava-se pigmento marrom-alaranjado na submucosa e lâmina própria. Áreas multifocais com ulcerações da mucosa e nódulos esbranquiçados na serosa foram observadas tanto no intestino grosso quanto no delgado. O Caprino 1.2 e o Ovino 1.1, que não apresentavam sinais clínicos da enfermidade, tinham a mucosa do íleo e jejuno discretamente enrugado com até $0,2 \mathrm{~cm}$ de espessura. O Caprino 1.2 apresentava a mucosa do duodeno levemente avermelhada. Todos os animais com exceção do Caprino 1.2 tinham os vasos linfáticos do mesentério dilatados. Todos os animais apresentavam Cysticercus tenuicollis na cavidade abdominal.

\section{Alterações microscópicas.}

No Caprino 1.1 o jejuno e o íleo estavam com a lâmina própria e a submucosa distorcida e distendida por infiltrado inflamatório difuso e acentuado, constituído predominantemente por macrófagos espumosos e poucos linfócitos e plasmócitos (Fig.5). No Ovino 2.1, tanto no intestino

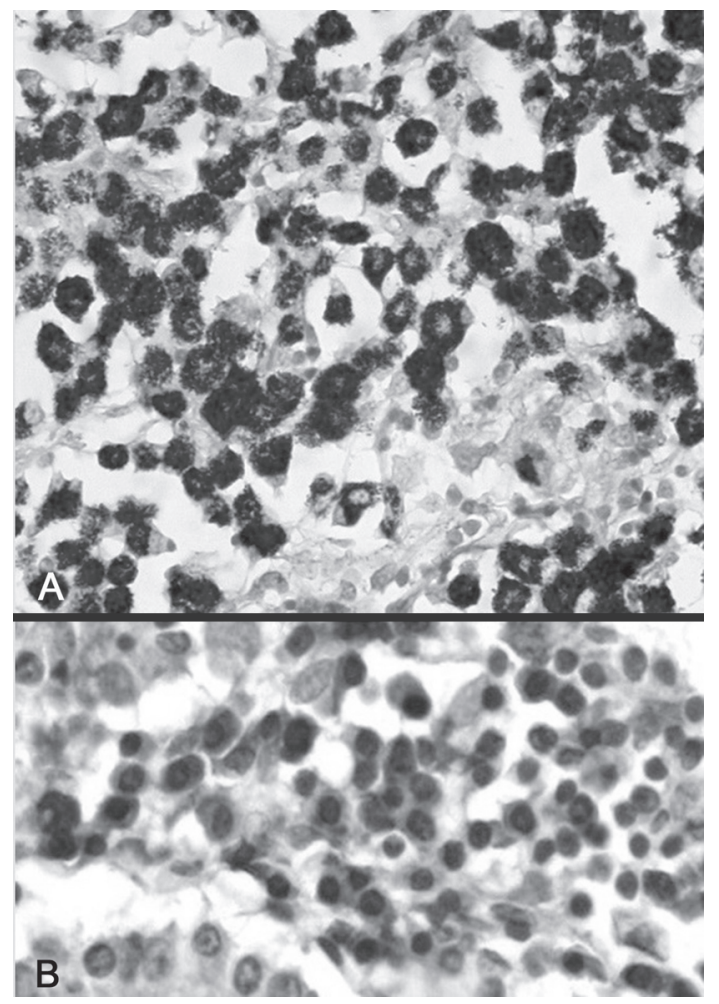

Fig.5. Lesão multibacilar difusa no íleo do Caprino 1.1. (A) Bacilos álcool-ácido resistentes no citoplasma de macrófagos. Coloração de Ziehl-Neelsen, obj.40x. (B) Marcação positiva para Mycobacterium spp. Imuno-histoquímica, obj.40x. 
delgado quanto no ceco, a lâmina própria e submucosa estavam distendidas e distorcidas por infiltrado inflamatório difuso ou em aglomerados compostos por macrófagos espumosos, por vezes, com pigmento marrom no citoplasma, células epitelióides, linfócitos, plasmócitos, eosinófilos e, no duodeno, raras células gigantes. Havia edema na mucosa do ceco e reto. O cólon e reto apresentavam discreto infiltrado predominante linfoplasmocitário difuso na lâmina própria. O mesmo infiltrado foi ocasionalmente observado ao redor de vasos na serosa. Havia hiperplasia das placas de Peyer.

No Ovino 1.1, positivo à tuberculina aviária, e no Caprino 1.2, negativo, ambos sem sinais clínicos da enfermidade, a lâmina própria do intestino delgado e ceco apresentavam infiltrado difuso de leve a moderado, preferentemente de linfócitos e com menor freqüência, macrófagos, plasmócitos e eosinófilos.

Nos linfonodos mesentéricos do Ovino 2.1. observaramse aglomerados de macrófagos espumosos ocasionalmente com pigmento amarronzado no interior do citoplasma, células epitelióides, eosinófilos, células gigantes e áreas de necrose, na região cortical, medular e seios perinodulares. Os linfonodos mesentéricos do Caprino 1.1. apresentavam características semelhantes aos do Ovino 2.1., mas com ausência de células gigantes. Nos linfonodos mesentéricos do Caprino 1.1 e do Ovino 2.1 havia depleção linfóide.

No fígado do Caprino 1.1 havia microgranulomas multifocais distribuídos aleatoriamente, constituídos por macrófagos espumosos e linfócitos. No rim do mesmo caprino havia cilindros hialinos e gotas hialinas no interior de túbulos contornados. No miocárdio do Caprino 1.2 havia áreas multifocais, discretas, de infiltrado linfohistiocitário. Hiperqueratose ortoqueratótica e acantose da epiderme foram observadas nas áreas alopécicas da pele do Caprino 1.1 e Ovino 2.1.

Nas secções coradas com método de Ziehl-Neelsen encontravam-se bacilos álcool-ácido resistentes no citoplasma de macrófagos (Fig.5A) e linfócitos. Na imunohistoquímica foi observada marcação positiva para $\mathrm{Myco-}$ bacterium spp. no interior do citoplasma de macrófagos (Fig.5B) e outros tipos de células linfóides.

\section{DISCUSSÃO}

Os resultados apresentados aqui confirmam a existência da paratuberculose em caprinos e ovinos na Paraíba e alertam para a possível ocorrência da doença nessas espécies de pequenos ruminantes em outras regiões do Brasil. O sinal clínico mais característico dessa doença em caprinos e ovinos é o emagrecimento acentuado, na maioria das vezes, sem diarréia, o que facilita a confusão com diversas doenças infecciosas, parasitárias e nutricionais. Novos trabalhos deverão ser realizados para determinar a prevalência e os prováveis prejuízos econômicos da enfermidade.

Um aspecto importante a ser levado em consideração é o da saúde pública. Mycobacterium avium subsp. paratuberculosis é provavelmente a causa da doença de Crohn e uma das mais prováveis vias de transmissão é o leite de vacas contaminadas e seus subprodutos (Slana et al. 2009). Em conseqüência do fato da doença afetar caprinos leiteiros, o consumo de leite de cabras poderia representar risco de transmissão para o homem. Outras possíveis vias de transmissão da doença dos pequenos ruminantes para o homem devem ser também consideradas.

As lesões macroscópicas observadas são características da enfermidade. $O$ espessamento segmentar observado na ovelha foi descrito por Carrigan \& Seaman (1990) e Clarke \& Little (1996). A pigmentação amarelo-laranja na mucosa do intestino é relatada em ovinos, especialmente na Inglaterra, sendo causadas por estirpes de micobactérias pigmentadas (Clarke \& Little 1996). A ausência das lesões macroscópicas do intestino, como observada no Caprino1.1, é comum nos caprinos (Corpa et al. 2000, Barker 2007), daí a importância do exame histopatológico do íleo, válvula ileocecal e linfonodos mesentéricos.

Em relação à classificação das lesões intestinais e dos linfonodos mesentéricos dos animais que apresentaram a forma clínica da doença, o Caprino 1.1 apresentou uma lesão multibacilar difusa (Corpa et al. 2000) e o Ovino 2.1 uma forma lepromatosa do Tipo 3b (Pérez et al. 1996). Nos animais com a forma subclínica ficou caracterizada uma enterite linfocítica difusa (Pérez et al. 1996, Corpa et al. 2000). As lesões de paratuberculose no fígado do Caprino 1.1 provavelmente são conseqüentes à diminuição da imunidade celular associada à progressão da enfermidade (Sweeney et al. 1992).

Neste trabalho o diagnóstico foi realizado pela presença de enterite e linfadenite granulomatosa, que são lesões características da doença, e pela presença de bacilos álcool-ácido resistentes, com marcação positiva para $\mathrm{Myco-}$ bacterium spp. na imuno-histoquímica. Os resultados da tuberculinização, observados tanto na técnica comparativa quanto na simples para $M$. avium, considerando o alto número de animais com diagnóstico inconclusivo nas fazendas 1 e 2, e a não detecção de um animal com lesões na Fazenda 1, sugerem que esse método é pouco eficiente para o diagnóstico da doença subclínica.

Para o futuro do controle da doença, assim como para avaliar e diminuir os riscos de contaminação humana, deverão ser desenvolvidas outras técnicas de diagnóstico, incluindo a determinação de anticorpos séricos pelo ELISA e técnicas de PCR para identificação do MAP em leite (Kumar et al. 2007, Radostits et al. 2007, Riet-Correa \& Driemeier 2007). Sem a utilização dessas ou outras técnicas para a identificação de animais afetados subclinicamente é difícil estabelecer formas de controle da doença nas fazendas onde foi diagnosticada a mesma. Apesar disso devem ser recomendadas medidas gerais, como a eliminação de animais que apresentem emagrecimento progressivo, higiene adequada das instalações e outras medidas que evitem o contato com matérias fecais, principalmente dos cordeiros e cabritos.

Agradecimentos.- À CAPES pela concessão da bolsa de mestrado. Este projeto foi financiado pelo CNPq (Proc. 471783/2008-0). 


\section{REFERÊNCIAS}

Barker I.K. 2007. The alimentary system, p.1-296. In: Maxie M.G., Jubb Kennedy \& Palmer (Eds), Pathology of Domestic Animals. Vol.2. $5^{\text {th }}$ ed. Elsevier, Oxford.

Carrigan M.J. \& Seaman J.T. 1990. The pathology of Johne's disease in sheep. Aust. Vet. J. 67(2):47-50.

Chamberlin W., Graham D.Y., Hulten K., El-Zimaity H.M.T., Schwartz M.R., Naser S., Shafran I. \& El-Zaatari F.A.K. 2001. Review article: Mycobacterium avium subsp. paratuberculosis as one cause of Crohn's disease. Aliment. Pharmacol. Ther. 15(3):337-346.

Chiodini R.J. \& Rossiter C.A. 1996. Paratuberculosis: A potential zoonosis? Vet. Clin. North. Am. Food. Anim. Pract. 12(2):457-467.

Clarke C.J. 1997. The pathology and pathogenesis of paratuberculosis in ruminants and other species: A review. J. Comp. Pathol. 116(3):217261.

Clarke C.J. \& Little D. 1996. The pathology of ovine paratuberculosis: Gross and histological changes in the intestine and other tissues. J. Comp. Pathol. 114(4):419-437.

Corpa J.M., Garrido J., García Marín J.F. \& Pérez V. 2000. Classification of lesions observed in natural cases of paratuberculosis in goats. J. Comp. Pathol. 122(4):255-265.

Harris N.B. \& Barletta R.G. 2001. Mycobacterium avium subsp. paratuberculosis in veterinary medicine. Clin. Microbiol. 14(3):489-512.

Ilha M.R.S., Barros C.S.L., Bezerra P.S. \& Langohr I.M. 1998. Paratuberculose em um bovino no Rio Grande do Sul. 13ª Jornada Acadêmica Integrada, Santa Maria, RS, p.450. (Resumo)

Kumar P., Singh S.V., Bhatiya A.K., Sevilla I., Singh A.V., Whittington R.J., Juste R.A., Gupta V.K., Singh P.K., Sohal J.S. \& Vihan V.S. 2007. Juvenile capri-paratuberculosis (JCP) in India: Incidence and characterization by six diagnostic tests. Small Rum. Res. 73(1-3):4553.

Moravkova M., Hlozek P., Beran V., Pavlik I., Preziuso S., Cuteri V. \& Bartos M. 2008. Strategy for the detection and differentiation of Mycobacterium avium species in isolates and heavily infected tissues. Res.Vet. Sci. 85(2):257-264.

Mota R.A., Pinheiro Junior J.W., Gomes M.J.P., Peixoto R.M., Maia F.C.L., Brito M.F., Chies J.A.B., Snel G.G.M., Bercht B.S. \& Juffo
G.D. 2007. Paratuberculose em um rebanho bovino leiteiro no estado de Pernambuco, PE. Arqs Inst. Biológico, São Paulo, 74(2):73-79.

Oliveira D.M., Pimentel L.A., Rodrigues T.A., Dantas A.F.M., Neto E.G.M., Simões S.V.D. \& Riet-Correa F. 2008. Paratuberculose em bovinos no estado da Paraíba. Encontro Nacional de Diagnóstico Veterinário (Endivet), Campo Grande, MS, p.203-204. (Resumo)

Ott S.L., Wells S.J. \& Wagner B.A. 1999. Herd-level economic losses associated with Johne's disease on US dairy operations. Prev. Vet. Med. 40(3/4):179-192.

Pérez V., García Marín J.F. \& Badiola J.J. 1996. Description and classification of different types of lesion associated with natural paratuberculosis infection in sheep. J. Comp. Pathol. 114(2):107-122.

Poester F.P. \& Ramos E.T. 1994. Infecção experimental em caprinos com Mycobaterium paratuberculosis de origem bovina. Ciência Rural 24(2):333-337.

Radostits O.M., Gay C.C., Hinchcliff K.W. \& Constable P.T. 2007. Veterinary Medicine. $10^{\text {th }}$ ed. Saunders Elsevier, Edinburgh, p.10171044.

Riet-Correa F. \& Driemeier D. 2007. Paratuberculose, p.407-414. In: Riet-Correa F., Schild A.L., Lemos R.A.A. \& Borges J.R.J. (Eds), Doenças de Ruminantes e Eqüinos. Vol.1. $3^{\mathrm{a}}$ ed. Pallotti, Santa Maria, RS.

Silva N.M. 1968. Estudos sobre a paratuberculose. IV. Infecção experimental de ovinos com Mycobacterium paratuberculosis de origem bovina. Pesq. Agropec. Bras. 3:285-289.

Singh S.V., Singh A.V., Singh P.K., Gupta V.K., Kumar S. \& Vohra J. 2007. Sero-prevalence of paratuberculosis in young kids using 'Bison type', Mycobacterium avium subsp. paratuberculosis antigen in plate ELISA. Small Rum. Res. 70(2-3):89-92.

Slana I., Liapi M., Moravkova M., Kralova A. \& Pavlik I. 2009. Mycobacterium avium subsp. paratuberculosis in cow bulk tank milk in Cyprus detected by culture and quantitative IS900 and F57 real-time PCR. Prev. Vet. Med. 89(3/4):223-226.

Sweeney R.W., Whitlock R.H. \& Rosenberger A.E. 1992. Mycobacterium paratuberculosis isolated from fetuses of infected cows not manifesting signs of the disease. Am. J. Vet. Res. 53:477-480.

Taylor T.K., Wilks C.R. \& McQueen D.S. 1981. Isolation of Mycobacterium paratuberculosis from the milk of a cow with Johne's disease. Vet. Rec. 109(12):532-533. 